\title{
Electrical injury on removal of implantable defibrillator after death
}

\author{
D Ghosh, M A James, R B G Palmer
}

Department of

Cardiology, Musgrove

Park Hospital,

Taunton, Somerset,

United Kingdom

D Ghosh

M A James

R B G Palmer

Correspondence to:

Dr James, Department of

Cardiology, Taunton \&

Somerset NHS Trust

Hospital, Musgrove Park,

Taunton, Somerset

TA1 5DA, United Kingdom.

Accepted for publication 19 February 1997

\begin{abstract}
A 76 year old man with a longstanding history of coronary artery disease, previous coronary artery bypass graft, and poor left ventricular function was implanted with an implantable cardioverter-defibrillator (ICD) (Medtronic Jewel) in August 1994 because of drug resistant syncopal ventricular tachycardia (VT) and fibrillation (VF). The superior vena cava and ventricular leads were introduced via the left cephalic vein. The device was installed in a left infraclavicular pocket. The defibrillation threshold was $12 \mathrm{~J}$. He remained well and the ICD was needed only occasionally; five episodes in one year (three VT and two VF, all terminated successfully). The patient died at home in his sleep in April 1996, presumably from progressive coronary artery disease.

Interrogation of the device showed that the patient had had three episodes of VT at the probable time of death that were terminated successfully. The device had continued providing rate support pacing from the time of the last VT therapy until the time of its removal. It seems likely that he suffered an acute coronary event at the time of these episodes of VT, and then developed a low output state or perhaps electromechanical dissociation as a terminal event following the arrhythmia.
\end{abstract}

The patient's general practitioner was asked to remove the ICD before cremation. The doctor was practised in the removal of pacemaker devices and was in the habit of washing them once removed. While he was washing the leads under running water he received an electrical shock which burned his thumb and middle finger and damaged the stainless steel sink. He was not wearing gloves at the time.

The device was returned to us and interrogation showed the episodes of VT and rate support pacing already described. It also revealed that during the washing process artefact was sensed as an episode of VF and the device delivered a shock (fig 1).

We tested the device further in our own department. The electrodes and device were rinsed under running tap water for a couple of minutes and then interrogated. The artefacts generated by washing were sensed as VF and a therapy sequence was initiated (fig 2 ).

Neither we nor the manufacturers are aware of any reports of electrical injuries sustained during the removal of ICD devices after death. There has been one report of a paramedic crew member who received an electrical shock while giving cardiopulmonary bypass to a patient with an ICD in VF. ${ }^{1}$ The potential for these devices to cause electrical injuries has not previously been considered and is not addressed in any of the manufacturers' guidelines or other articles which discuss potential complications. ${ }^{2-5}$

This case clearly demonstrates that there is a potential for electrical injury when handling an explanted ICD and this could have led to a

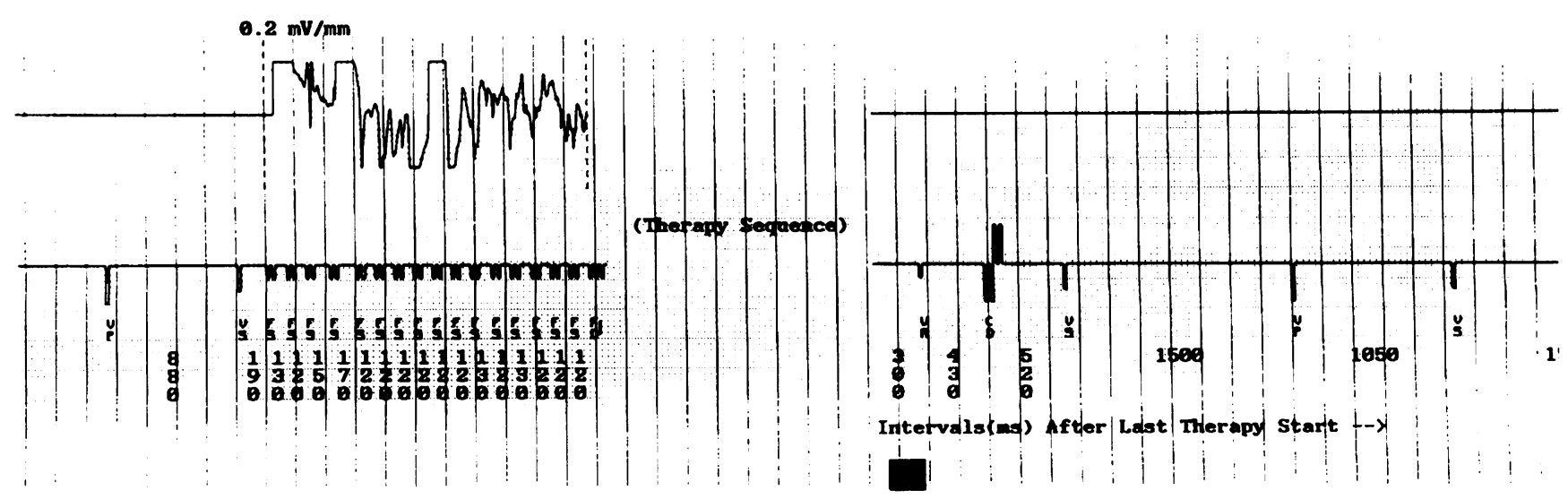

Figure 1 ICD therapy during the injury. Upper channel, intracardiac ECG signals; Lower channel, pacemaker sensing and marker channel. $V S$, ventricular sensed beat; VP, ventricular paced beat; FS, fibrillation sensed beat; FD, fibrillation detected. 


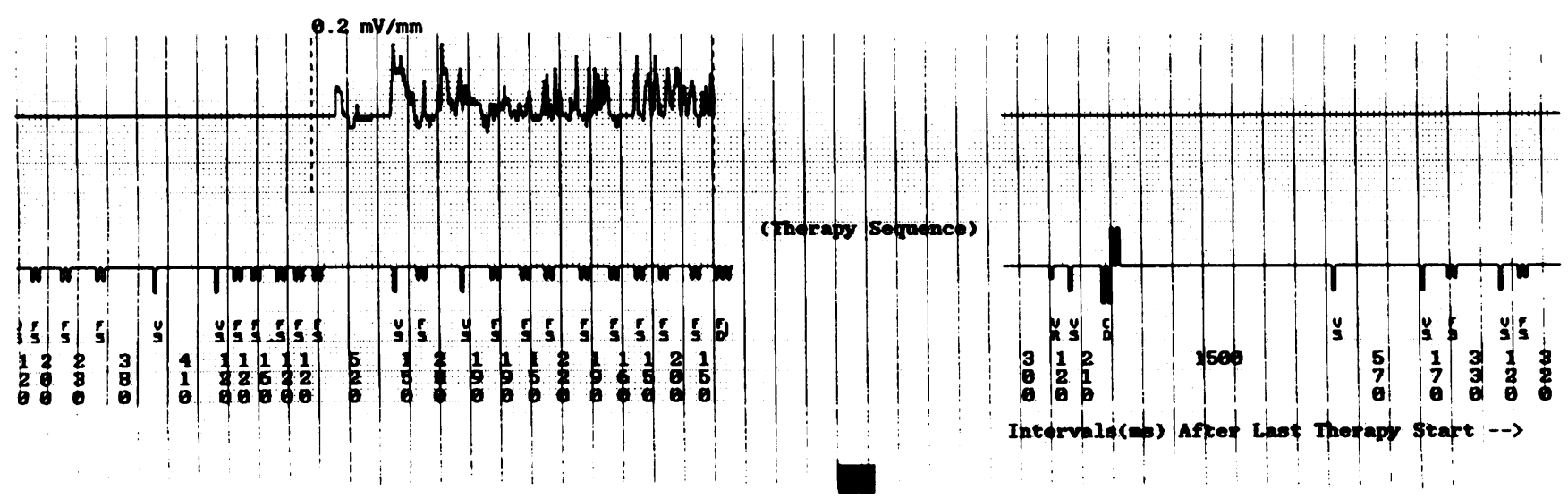

Figure 2 ICD therapy induced by washing leads in the laboratory. Upper channel, intracardiac ECG signals; Lower channel, pacemaker sensing and marker channel. VS, ventricular sensed beat; VP, ventricular paced beat; FS, fibrillation sensed beat; FD, fibrillation detected.

far more serious result and possible fatality. It is clear that guidelines should be issued for the benefit of personnel who may be required to explant any devices particularly where there is potential for harm. As new devices are developed, guidelines for their removal should be supplied at the same time as the introduction of the unit. It seems logical that the manufacturers should be responsible for producing a set of guidelines, although these may need modification in the light of experience.

We suggest that when an ICD is removed the electrodes should be cut off close to their connection with the generator using wirecutters with adequate insulation, and wearing rubber gloves. Once disconnected the generator can be removed safely and the leads can be left inside the body.

1 Lechleuthner A. Electric shock to paramedic during cardiopulmonary resuscitation of patient with implanted cardiodefibrillator [letter]. Lancet 1995;345:253.

2 Williams J M, Rock DT, Pabst SJ, Grill CR, DeAntonio HJ, Mahmud R, et al. Clinical experience with the implantable cardioverter defibrillator. Ann Thorac Surg 1994;58:1297-303.

3 Jones GK, Bardy GH, Kudenchuk PJ, Poole JE, Dolak GL, Troutman C, et al. Mechanical complications after implantation of multiple-lead nonthoracotomy defibrillator systems: implications for management and future system design. Am Heart $\mathcal{F}$ 1995;130:327-33.

4 Fahy GJ, Kleman JM, Wilkoff BL, Morant VA, Pinski SL Low incidence of lead related complications associated with nonthoracotomy implantable cardioverter defibrillator systems. Pacing Clin Electrophysiol 1995;18:172-8.

5 Clemo HF, Ellenbogen KA, Belz MK, Wood MA Stambler BS. Safety of pacemaker implantation in patients with transvenous (nonthoracotomy) implantable cardioverter defibrillators. Pacing Clin Electrophysiol 1994; 17:2285-91. 